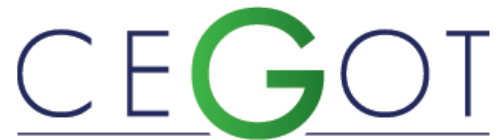

Centro de Estudos de Geografia e Ordenamento do Território
SILVA, SUSANA

Universidade de Coimbra - Centro de Estudos de Geografia e

Ordenamento do Território (CEGOT), Faculdade de Letras.

Universidade de Coimbra, Colégio de S. Jerónimo, 3004-530, Coimbra, Portugal. susana.silva@uc.pt

FERREIRA, LÍDIA

Escola Superior de Educação e Ciências Sociais - Politécnico de

Leiria.

Campus 1, Rua Dr. João Soares, Apartado 4045, 2411-901 Leiria, Portugal.

lidia.ar.ferreira@alunos.ipb.pt

\title{
Turismo e desenvolvimento sustentável. Uma avaliação exploratória das práticas hoteleiras no concelho de Bragança, Portugal
}

Tourism and sustainable development. An exploratory evaluation of hotel practices in the municipality of Bragança, Portugal

Referência: Silva, Susana; Ferreira, Lídia (2021). Turismo e desenvolvimento sustentável. Uma avaliação exploratória das práticas hoteleiras no concelho de Bragança, Portugal. Revista de Geografia e Ordenamento do Território (GOT), n.o 21 (Junho). Centro de Estudos de Geografia e Ordenamento do Território, p. 235-262, dx.doi.org/ 10.17127/got/2021.21.010

\section{RESUMO}

O turismo sustentável constitui uma das preocupações da Agenda 2030 para o Desenvolvimento Sustentável que, embora não seja recente, ganha cada vez mais força e espaço nos discursos e nas políticas do turismo, pelo que os princípios da sustentabilidade têm vindo a ser incorporados no comportamento e procedimentos dos agentes envolvidos na atividade de modo a minorar os efeitos negativos. Do setor hoteleiro, parte ativa neste processo, é exigida cada vez mais uma atitude conscienciosa, assim como a adoção de medidas e padrões de conduta que procurem reduzir os seus impactes socioambientais.

Este trabalho propõe avaliar as práticas de sustentabilidade nas dimensões ambiental, económica e social, assim como o seu grau de aplicabilidade, por parte do setor hoteleiro do concelho de Bragança, nordeste transmontano, a partir dos dados recolhidos através de um inquérito por questionário aos gestores/administradores de todas as unidades de alojamento turístico presentes neste território. Com recurso ao programa de análise estatística SPSS foi realizada uma análise estatística exploratória e descritiva.

Os resultados revelaram um nível de sustentabilidade hoteleira moderado, sugerindo que a adoção de práticas sustentáveis é ainda incipiente. Depreende-se, portanto, que há ainda muito a ser feito para que as unidades hoteleiras de Bragança contribuam de forma efetiva para o turismo sustentável. Embora este trabalho seja restrito a um pequeno território abre uma janela de oportunidade para a replicação desta metodologia, noutros territórios ou 
mesmo a nível nacional, incluindo um maior número de unidades assim como indicadores mais específicos e adaptados.

Palavras-chave: Turismo sustentável, práticas hoteleiras, nível de sustentabilidade, Bragança.

\begin{abstract}
Sustainable tourism is one of the concerns of the 2030 Agenda for Sustainable Development, which, although not recent, is gaining more strength and space in the discourses and policies about tourism. Thus the principles of sustainability have been incorporated into the behavior and procedures of the agents involved in the activity in order to mitigate the negative effects. The hotel sector, an active part in this process, is increasingly demanding a conscientious attitude, as well as the adoption of measures and standards of conduct that seek to reduce its socio-environmental impacts.

This work proposes to evaluate sustainability practices in the environmental, economic and social dimensions, as well as their degree of applicability, by the hotel sector in the municipality of Bragança, northeast of Trás-os-Montes, from the data collected through a questionnaire survey to managers of all tourist accommodation units. An exploratory and descriptive statistical analysis was performed using the SPSS statistical analysis program.

The results revealed a moderate level of hotel sustainability, suggesting that the adoption of sustainable practices is still incipient and that much still remains to be done for the hotels in Bragança to contribute effectively to sustainable tourism. Although this work is restricted to a small territory it opens a window of opportunity to replicate this methodology, in other territories or even at national level, including a larger number of units as well as more specific and adapted indicators.
\end{abstract}

Keywords: Sustainable tourism, hotel practices, sustainability level, Bragança.

\title{
1. Introdução
}

A degradação ambiental tornou-se há muito num dos mais sérios desafios globais e, desde então, muitas empresas enfrentam a inevitável pressão de terem de adotar atitudes e procedimentos inovadores objetivando vantagens económicas mas que, paralelamente, sejam consentâneas com a preservação do ambiente (Li et al., 2017). A construção de uma sociedade economicamente viável, socialmente justa, culturalmente compatível e responsável em termos ambientais tornou-se, assim, numa preocupação transversal aos diversos setores da economia, inclusive aqueles relacionados com o turismo no geral, e com a hospitalidade em particular (Santos, Mexas, \& Meiriño, 2017), em muito pressionados pela procura, entidades organizacionais, stakeholders, entre outros, cada vez mais conscientes da importância e necessidade da adoção de práticas sustentáveis (Bader, 2005). 
Em harmonia com estas prerrogativas, as Nações Unidas aprovaram, em 2015, a resolução "Transforming our World: the 2030 Agenda for Sustainable Development" consubstanciada em 17 objetivos de desenvolvimento sustentável e 169 metas, almejando a criação de um novo modelo global de desenvolvimento assente no crescimento económico sustentado e inclusivo, na coesão social e na proteção ambiental (UN, 2015).

O turismo ocupa um papel bastante relevante na economia mundial tendo-se tornado num forte catalisador do desenvolvimento económico (Rodríguez-Anton, Alonso-Almeida, Celemín, \& Rubio, 2012) e, como tal, entendido como um instrumento vital para este desenvolvimento sustentável já que, quando bem planeado, constitui uma arma na luta contra a pobreza, sobretudo ao nível da geração de oportunidades de emprego, da proteção do ambiente e da melhoria da qualidade de vida através das receitas geradas, e ainda do aumento da consciência sobre os problemas ambientais (UN, 2016, citada em Santos et al., 2020). A atividade turística é, deste modo, encarada pelos destinos como uma oportunidade para desenvolver a estrutura de acolhimento local e expandir as suas receitas criando negócios e empregos. Entre estes destacam-se as empresas hoteleiras devido aos variados serviços recreativos, de entretenimento e facilidades para encontros e reuniões que oferecem (Santos et al., 2017).

Porém, se por um lado são evidentes os diversos impactes positivos do crescimento da atividade turística, e da hoteleira em particular, ao nível do desenvolvimento socioeconómico, num país ou numa região, também é consensual que esse crescimento acarreta um conjunto de consequências negativas significativas para a sociedade mas, sobretudo, para o ambiente (Mihalič, 2000). As previsões indicam que o consumo turístico de recursos, como energia, água potável, solo e alimentos, está cada vez mais intenso, duplicando em 25-45 anos (Gossling \& Peeters, 2015).

O setor da hotelaria vê-se então confrontado com pressões externas e internas, provenientes não só dos clientes, cada vez mais conscientes, mas também das regulamentações governamentais, das agências ambientais, shareholders, staff e de negócios concorrentes, para implementar medidas amigas do ambiente e inovações sustentáveis (Erdogan \& Baris, 2007), sobretudo ao nível da redução de desperdício, energia e água (Rahman, Reynolds, \& Svaren, 2012), levando à proliferação de processos de certificação (Gössling \& Buckley, 2016). Todavia, a real adoção e eficácia dessas inovações é 
questionada. Este segmento é frequentemente criticado pela discrepância entre atitude e ação, ou seja, embora se verifique uma perceção geral de que o alojamento turístico reconhece a importância da ecologia nos seus negócios, falham na implementação dessas práticas amigas do ambiente (Bohdanowicz, 2006).

Bragança é um dos concelhos do nordeste transmontano cujas vicissitudes de um território de fronteira são sobejamente conhecidas e se vêm agudizando ao longo do tempo, mormente a nível demográfico, mas cuja interioridade não foi interiorizada como uma limitação, antes pelo contrário, é defendida uma posição geográfica privilegiada no contexto ibérico, beneficiando nos últimos anos do investimento em vias de comunicação, justificado pela exaustivamente repetida "coesão territorial". A $90 \mathrm{~km}$ de Zamora, $170 \mathrm{~km}$ de Salamanca, $200 \mathrm{~km}$ de Valladolid, $360 \mathrm{~km}$ de Madrid (mais perto que Lisboa) ou a pouco mais de $200 \mathrm{~km}$ do Porto, Bragança recusa a posição marginal que the atribuem. Não obstante, a dinâmica demográfica negativa é uma realidade. Regista-se uma perda da população residente e um consecutivo envelhecimento populacional. O Instituto Politécnico de Bragança constitui um elemento importante que tem contrariado algum esvaziamento populacional, social e económico.

O crescimento da atividade turística a nível nacional tem tido tradução também nesta região. Dados do INE (2019) revelam que Bragança tem uma posição de destaque na sua sub-região, Terras de Trás-os-Montes, no que diz respeito ao número de estabelecimentos (26\%), capacidade de alojamento (39\%), hóspedes (46\%) ou dormidas (46\%), indicadores turísticos que registam incrementos importantes, sobretudo ao nível das unidades de alojamento.

Este estudo tem como objetivo avaliar as práticas de sustentabilidade nas dimensões ambiental, sociocultural e económica, assim como o seu grau de aplicabilidade, por parte do setor hoteleiro do concelho de Bragança, a partir dos dados recolhidos através de um inquérito por questionário aos gestores/administradores de todas as unidades de alojamento turístico presentes neste território. Com recurso ao programa de análise estatística SPSS foi realizada uma análise estatística exploratória e descritiva. Não obstante o carácter exploratório deste trabalho, os resultados apurados podem constituir uma ferramenta útil para os meios de alojamento deste concelho, pelo menos na tomada de 
consciência sobre o nível atual de aplicabilidade das práticas gerais destas unidades e dos progressos realizados, podendo influenciar futuros comportamentos, atitudes e ações.

\section{Desenvolvimento sustentável e sustentabilidade no turismo}

A Conferência das Nações Unidas sobre o Meio Ambiente Humano, realizada em Estocolmo (Suécia) em 1972, corresponde à concretização de uma discussão que já se havia delineado anos antes relativamente ao processo de desenvolvimento, à finitude dos recursos naturais e por consequência à diminuição da qualidade de vida. Por esta altura já o turismo havia sido considerado uma indústria de massas e reconhecidas as fortes pressões sobre os recursos naturais e comunidades locais dos principais destinos turísticos a nível mundial sendo admitido, pela primeira vez, na Conferência Mundial do Turismo em 1980, que o "turismo prejudica mais do que beneficia as sociedades do terceiro Mundo" (Santos, Barbosa, \& Bártolo, 2009). O conceito de sustentabilidade posiciona-se definitivamente como um elemento fundamental a considerar no âmbito da atividade turística e a fundação da Organização Mundial do Turismo (OMT) desempenhou um papel decisivo na sua promoção e no alerta do quanto é crucial mudar paradigmas, posição consolidada ao longo do tempo.

O Relatório Brundtland, de 1987, foi o culminar de uma série de iniciativas e discussões sobre ambiente e desenvolvimento e onde é cunhado o conceito de desenvolvimento sustentável, entendido como aquele que satisfaz as necessidades do presente sem comprometer a capacidade das gerações futuras satisfazerem as suas próprias necessidades, pautado por um equilíbrio entre necessidades humanas e ambiente, sendo a sustentabilidade considerada como uma via para alcançar um desenvolvimento humano durável pressupondo, deste modo, uma visão de longo prazo (UN, 1987). Tal decorre da visão crítica do modelo de desenvolvimento adotado pelos países desenvolvidos e reproduzido pelos países em vias de desenvolvimento, caracterizado por ser "ecologicamente predatório, socialmente perverso e politicamente injusto" (Borges, Ferraz, \& Borges, 2015, p. 605). Com a publicação deste Relatório surge a necessidade de incorporar a sustentabilidade nas organizações que começam a ter perceção da sua responsabilidade nos impactes negativos produzidos a curto, médio e longo prazo (Kasim, 
Gursoy, Okumus, \& Wong, 2014) assim como na preservação do ambiente, muito embora esta responsabilidade ambiental tenha sido impulsionada, num primeiro momento, pela legislação (Kim \& Statman, 2012).

O conceito de desenvolvimento sustentável é consagrado e ampliado mais tarde pela Cimeira da Terra (1992) onde quase 200 países adotaram um programa de ação - a Agenda 21 - que identificou os principais problemas ambientais do planeta e propôs uma estratégia de transição no modelo de desenvolvimento. As consequências ambientais, sociais e económicas advindas da atividade turística começam a agudizar-se justamente na década de 90, repercutindo em muito a falta de planeamento assente em pressupostos de sustentabilidade, dando origem a vários impactes negativos (Careto \& Lima, 2006). No decorrer dos anos, diversos foram os documentos produzidos e publicados com o objetivo de incorporar a responsabilidade ambiental e sociocultural nas práticas da atividade turística (Santos et al., 2009). Entre os mais marcantes estão a Carta do Turismo Sustentável de 1995, que conhece nova versão em 2015, e a Agenda 21 para a Indústria de Viagens e Turismo para o Desenvolvimento Sustentável (1996). A definição de princípios e orientações, com vista a um turismo mais sustentável na sua conceção holística, norteadoras de ações e procedimentos, é transversal a todos estes documentos.

Na perspetiva da OMT, o turismo sustentável deve fazer um uso otimizado dos recursos ambientais, respeitar a autenticidade sociocultural das comunidades acolhedoras e providenciar benefícios socioeconómicos viáveis, de longo prazo a todos, esclarecendo ainda que o turismo sustentável não é uma forma distinta ou especial de turismo, pelo contrário, todas as formas de turismo devem esforçar-se para serem sustentáveis, incluindo aquele que é conhecido como turismo de massas (WTO, 2011).

O turismo, que demonstra um crescimento sem precedentes, é encarado como um predador de recursos estando-Ihe associada uma enormidade de impactes negativos a diversos níveis, com particular incisão no ambiente. De acordo com o estudo de Lenzen et al. (2018), o turismo é o principal contribuidor das emissões de $\mathrm{CO}^{2}$, revelando ainda que a pegada global de carbono do turismo representou cerca de $8 \%$ das emissões globais de gases de efeito estufa, uma pegada para a qual contribuem as atividades turísticas, como o transporte, a alimentação, o comércio e o alojamento. Não obstante, o turismo tem reconhecido a importância da qualidade ambiental para assegurar a existência futura da 
maioria dos destinos turísticos, até porque a qualidade ambiental de um destino é uma questão predominante na tomada de decisões relacionadas a viagens constituindo um fator de competitividade entre diferentes destinos turísticos (Mihalič, 2000). No sentido de dar resposta e acompanhar as crescentes pressões, têm sido desenvolvidos diversos projetos e incorporadas medidas ambientais nas atuais estratégias de gestão objetivando, de alguma forma, minimizar esses impactes, nomeadamente no contexto do alojamento turístico (Bader, 2005).

\section{Meios de alojamento e sustentabilidade}

O desenvolvimento da atividade turística não teve só repercussões ao nível da densificação de fluxos, mas em toda a cadeia turística, nomeadamente num dos seus eixos fundamentais, os meios de alojamento (Erdogan \& Baris, 2007). Este setor é, a nível mundial, um dos que utiliza uma quantidade massiva de recursos, como energia, água, alimentos e produtos não duráveis através dos serviços proporcionados aos hóspedes, resultando, de igual modo, em grandes quantidades de resíduos e poluentes (Bohdanowicz \& Martinac, 2003; Nilashi et al., 2019). Os dados apurados por Lenzen et al. (2018) revelam que, em 2013, este setor foi responsável pela emissão de 282 milhões de toneladas de $\mathrm{CO}^{2}$, ocupando a 4a posição da pegada de carbono relacionada com bens adquiridos, para além do transporte. De acordo com Melissen, Koens, Brinkman e Smit (2016), o setor é responsável por $21 \%$ da pegada ecológica total do turismo, prevendo-se que alcance os $25 \%$ em 2035, para além de que, no âmbito da atividade turística, os maiores consumos de energia provêm dos hotéis, decorrentes da grande variedade de serviços disponibilizados aos hóspedes (Bohdanowicz, 2005), sendo, por isso, há muito identificado como responsável por danos e degradação do ambiente.

Data da década de 70 do século XX a incorporação da qualidade do ambiente como elemento de destaque do produto turístico (Ruschmann, 2001, citado em Borges et al., 2015) sendo cada vez mais reconhecida como parte integrante da qualidade do destino turístico e, como tal, um fator de competitividade deste, influenciando, de igual modo, a escolha do destino (Mihalič, 2000), já que o ambiente natural é frequentemente o principal motivador deste setor (Kadriu, 2016, citado em Preziosi et al., 2019). 
Embora inicialmente a hotelaria tenha respondido de forma lenta às solicitações ambientais até terem surgido vários programas de consciencialização ambiental nos anos 90, como o International Hotel Environmental Initiative ou o Environmental Action Pack for Hotels (Choi, Kim, Kim, \& Agmapisarn, 2019), Valente (2007, citado em Borges et al., 2015) relembra que já na década de 80 a rede hoteleira europeia utilizava técnicas para minimizar o uso da água e da energia elétrica. Porém, é sobretudo a partir da década de 90 que se processa uma modificação mais concreta neste sector, ao nível da edificação e da forma de operacionalizar as atividades, que, pressionado, começa a adotar uma atitude mais conscienciosa e rigorosa, procurando incorporar procedimentos e comportamentos mais consentâneos com os pressupostos da sustentabilidade, no sentido de garantir eficiência, qualidade e redução dos impactes socioambientais (Borges et al., 2015). A norma ISO 14001, datada desta década, voltada para um sistema de gestão da qualidade ambiental, é uma forte referência global e vai nortear a partir de então todas as ações empresariais, inclusive nos meios de hospedagem, para o uso adequado dos recursos e redução dos impactes ambientais (Borges et al., 2015), requerendo uma atitude pró-ativa e de procura de melhoria contínua.

Diversas e conhecidas cadeias hoteleiras mundiais reconheceram as vantagens de reduzir o seu impacte ambiental através de políticas e iniciativas amigas do ambiente que se tornaram cada vez mais populares (Bohdanowicz \& Martinac, 2003) e, na passagem para o século XXI, existiam empresas hoteleiras sustentáveis em vários estádios, localizadas em todos os continentes, em cidades, desertos e até nas selvas (Bader, 2005). São exemplo o Marriott, Hilton, Fairmont, Starwood, Accor, Rezidor, Shangri-La ou Taj Hotels \& Resorts, que deram os primeiros passos no desenvolvimento de iniciativas e programas ambientais com o objetivo de minimizar os impactes das suas operações (Bader, 2005). Foram implementados sistemas de poupança e purificação de água, painéis solares, campanhas de poupança de energia, reduzidos materiais químicos na limpeza e lavandaria assim como os resíduos sólidos, utilizados materiais recicláveis ou biodegradáveis nos quartos, instalados termostatos digitais, introduzido um sistema de gestão ambiental ISO, para além da consciência e dedicação do staff. Medidas que, de acordo com Bader (2005), revelaram períodos de retorno interessantes e poupanças importantes com a implementação de 
certos sistemas, tendo repercussões ao nível da redução do consumo, da melhoria da imagem e consequentemente do aumento direto dos negócios.

Hoje em dia, os gestores hoteleiros estão bastante conscientes da importância e benefícios da adoção de estratégias ambientais ("green strategies") nas suas operações (Gupta, Dash, \& Mishra, 2019) e a considerar cada vez mais a importância da criação de valor e do desenvolvimento da reputação (Asadi et al., 2020). Também a legislação levou ao aumento da implementação de programas de gestão ambiental. Asadi et al. (2020) demonstram que a legislação ambiental pode afetar a inovação "verde" de forma positiva ao permitir que as organizações sejam pró-ativas, incentivando-as a desenvolver e implementar novas ideias, a atualizar instalações antigas ou a investir em tecnologia, para além de afetar de forma positiva e significativa o desempenho social, ambiental e económico.

Não obstante a procura constante pelos lucros, sendo a principal motivação essencialmente económica, é notória a necessidade que os meios de alojamento turístico sentem em investir na responsabilidade ambiental e social, de modo a garantirem um crescimento sustentável e a longo prazo, pelo que a implementação de estratégias de gestão que incluam a proteção da sociedade e do ambiente nas responsabilidades da empresa tem-se tornado uma prática comum neste setor (Yilmaz \& Yilmaz, 2016), apesar da crença generalizada de que as medidas ambientais têm um custo bastante elevado, o que constitui, ainda hoje, a maior barreira impeditiva dos empresários hoteleiros se tornarem mais ecológicos (Bohdanowicz \& Martinac, 2003; Fotiadisa, Vassiliadi, \& Rekleitis, 2013; Sloan, Legrand, \& Chen, 2013; Mak \& Chang, 2019). Porém, não obstante sejam necessários investimentos iniciais, foi demonstrado que estes são rentáveis a longo prazo (Bader, 2005).

Há autores que defendem não existirem evidências da relação entre uma gestão ambientalmente orientada e uma melhor performance financeira (Aznar, Sayeras, Galiana, \& Rocaforte, 2016), ou serem inconclusivas. Todavia, têm surgido estudos que, pelo contrário, evidenciam essa relação (Molina-Azorín, Claver-Cortes, Pereira-Moline, \& Tarí, 2009), para além de um incremento na satisfação entre os gerentes, funcionários e clientes (Bohdanowicz \& Zientara, 2008) e na satisfação e lealdade dos clientes (Preziozi et al., 2019). Existem, assim, vários exemplos a comprovar que hotéis que adotam práticas responsáveis e sustentáveis aumentam o volume de negócios, as receitas assim como os 
visitantes e o seu retorno. Estes apresentam-se como indicadores claros que os hóspedes conhecem e apoiam negócios e práticas sustentáveis nos alojamentos.

Em Portugal, assiste-se a um aumento da adesão do setor do alojamento turístico a práticas/tecnologias de utilização eficiente de energia, de água e gestão de resíduos (Sousa \& Eusébio, 2013). O relatório que analisa o desempenho de boas práticas (TP, 2020) revelou que, em 2019, 66\% dos empreendimentos turísticos declararam ter adotado medidas de utilização responsável dos recursos energéticos, 70\% das empresas declararam ter gerido de modo racional o recurso água e $60 \%$ das empresas declararam ter gerido de forma eficiente os resíduos. A meta estabelecida na Estratégia Turismo 2027 está fixada em mais de 90\% para estas três dimensões. Destaca-se com as mais altas percentagens a região da Madeira, sendo que o Norte ficou sempre abaixo do valor nacional. Em relação à dimensão energética a utilização de lâmpadas economizadoras (97\%), os sistemas de climatização com intensidade regulada pelo cliente (92\%) e o desligar dos equipamentos não necessários (88\%) são as mais aplicadas. No campo da gestão eficiente da água a mudança de toalhas e lençóis a pedido dos hóspedes ou de acordo com o legalmente exigido (95\%), o convite aos hóspedes para comunicarem perdas de água (87\%) assim como a utilização de redutores de caudal em torneiras e chuveiros (82\%) são as mais populares. No que diz respeito aos resíduos, destaca-se a separação dos resíduos para reciclagem (95\%) e a minimização da utilização de embalagens na restauração (67\%).

\subsection{A certificação ambiental}

Com o propósito de promover o turismo sustentável têm surgido diversas iniciativas, mormente normas definidoras dos requisitos para tal, aliadas a programas de certificação. A adoção de práticas sustentáveis e a consequente certificação do setor turístico decorre, em boa parte, de mudanças na procura, da emergência de um "novo turista", consciente, exigente, atento e preocupado com a questão ambiental, que cada vez mais seleciona o seu destino de férias com base em critérios ambientais e sociais (Bader, 2005; Mensah \& Mensah, 2013), da difusão e desenvolvimento das discussões em torno dos impactes ambientais, dos desafios que o setor hoteleiro enfrenta e das fortes pressões competitivas a 
que está sujeito, levando muitas companhias hoteleiras a encararem a certificação da qualidade como um fator estratégico (Hernández-Perlines, 2016).

A certificação é cada vez mais popular e difundida sendo considerada como uma ferramenta importante para promover o turismo sustentável. Tal, tem dado origem à proliferação de normas, programas de certificação e logótipos nesta área que atendem a parâmetros ambientais, sociais e económicos, destacando-se em larga maioria os ambientais. Porém, grande parte deles são merecedores de críticas devido não só à quantidade exagerada de rótulos ecológicos como às diferenças de padrões e critérios que comprometem comparações e, por inerência, a sua credibilidade e que, segundo Font (2002) e Bohdanowicz (2006), têm confundido e provocado alguma desconfiança nos consumidores que revelam dificuldade em distinguir quais estão associados a uma verdadeira responsabilidade ambiental e quais são apenas greenwashing, ao ponto destes preferirem desvalorizar e até mesmo ignorar estas "mensagens verdes". Nesta linha de pensamento, Bohdanowicz (2005) e Rahman et al. (2012) afirmam que a maior parte dos negócios tornase "verde" para atrair clientes, já que ao atraírem mais clientes, usando o que designam de "green apeal", regista-se um aumento da ocupação, das vendas e dos resultados, recaindo sobre elas desconfianças sobre a verdadeira motivação, que muitos apontam como sendo sobretudo de índole económica. Por um lado, há evidências que sugerem que estas são levadas a participar porque se sentem pressionadas pela legislação e querem evitar mais regulamentações ou a atenção dos reguladores e dos stakeholders, para disfarçar um pobre desempenho ambiental, e ainda porque querem captar o mercado dos "consumidores verdes" e alcançar uma "reputação verde" para obter mais benefícios, sem melhorarem realmente a sua performance ambiental (Font, 2002; Bohdanowicz, 2005, 2006).

Por outro lado, os verdadeiros "green hotels" objetivam certificar a sua performance ambiental superior e ganhar vantagens competitivas com base na diferenciação, constituindo assim uma oportunidade de sobressair sobre os demais empreendimentos no mercado (Rodríguez-Anton et al., 2012; Aznar et al., 2016). Na perspetiva de Bader (2005), o suporte, o reconhecimento e os prémios por práticas sustentáveis criam uma consciência positiva, para além de que podem atuar como catalisadores da procura e orientar o consumidor na escolha de produtos ou serviços com diferencial ambiental e social. Para além disso, alcançam também uma maior qualidade nos produtos e serviços, maior 
aceitabilidade por parte do consumidor e a captação de novos nichos de mercado, nomeadamente os que revelam alta exigência ambiental, assim como uma melhoria da imagem e reputação perante os clientes, obtêm níveis mais elevados de satisfação e fidelização dos clientes, podendo, de igual modo, traduzir-se em funcionários mais motivados, produtivos e empreendedores, melhores relações com a comunidade local e autoridades públicas, no aumento da poupança de custos e num diferencial para atrair empresários estrangeiros (Hernández-Perlines, 2016).

Existe um grande número de programas de certificação ambiental de hotéis internacionalmente reconhecidos como a certificação ISO14001, a Green Globe 21, a certificação Leadership in Energy and Environmental Design (LEED), a European Union EcoManagement and Audit Scheme (EMAS), a TripAdvisor Green Leaders, o Green Seal ou a Green Key (Choi et al., 2019), sendo transversal a prerrogativa do uso adequado dos recursos sem prejudicar a natureza através da utilização de técnicas de uso racional de água e da utilização de fontes de energia alternativas.

De acordo com o relatório do Turismo de Portugal sobre o desempenho ambiental do alojamento (TP, 2020), em 2019, 47\% das empresas declararam possuir pelo menos uma certificação ao abrigo de Normas Internacionais, um aumento de $16 \%$ face a 2017 , com destaque para a ISO 9001 (69\%) e ISO 14001 (52\%), e 3\% das empresas declararam possuir algum selo, distinção, galardão ou rótulo (+6\%). A região Norte sobressai, no primeiro caso, com uma percentagem superior à nacional, no segundo é a região da Madeira a destacar-se.

\section{Metodologia}

No sentido de verificar, de forma exploratória, o grau de utilização de práticas relacionadas com a sustentabilidade nos meios de alojamento foi aplicado um inquérito por questionário aos gestores/administradores ou responsáveis das unidades de alojamento no concelho de Bragança, entre final de dezembro de 2018 e meados de julho de 2019. Tomou-se como ponto de partida o Registo Nacional dos Empreendimentos Turísticos disponibilizado pelo Turismo de Portugal relativo aos empreendimentos turísticos e alojamento local registados no concelho e, após serem descartadas as unidades entretanto desativadas, as que praticavam exclusivamente a atividade de arrendamento a estudantes e os parques de 
campismo, chegou-se a um total de 73 unidades às quais foi enviado o questionário. Foram considerados todos os meios de alojamento em funções independentemente da sua dimensão.

O questionário foi elaborado com recurso à plataforma Google Docs tendo sido enviado o respetivo link por correio eletrónico. O baixo número de respostas verificado inicialmente (12 questionários) determinou a necessidade de reenvio uma segunda e terceira vez e do apelo à participação através de contactos telefónicos. No total, foram devolvidos 36 questionários, correspondendo a uma taxa de resposta de $49 \%$.

Este instrumento estava estruturado em duas partes: a primeira incluía questões relativas à identificação e caracterização da unidade, a segunda correspondia à avaliação da sustentabilidade ambiental, sociocultural e económica em cada unidade através de um conjunto de indicadores. Os indicadores foram selecionados com base no trabalho de Borges et al. (2015) ao qual se juntaram contributos próprios das autoras e organizados nas dimensões ambiental, sociocultural e económica (Tabela 1). Cada um dos indicadores foi testado a partir de uma escala Likert de 5 pontos, em que "0" foi considerada a pior situação possível associado à ausência de ocorrência (nunca aplicado) e "4" a situação mais desejável (sempre aplicado) associado à intensidade máxima da sua ocorrência.

Os dados recolhidos foram tratados, inseridos numa base de dados e analisados com recurso ao programa SPSS tendo sido utilizadas técnicas de análise estatística descritiva e de cruzamento de dados. Após a análise descritiva dos resultados, recorreu-se ao Índice de Sustentabilidade Hoteleira (ISH) desenvolvido por Borges et al. (2015) para quantificar o nível de sustentabilidade dos meios de alojamento neste território. Assim, o ISH corresponde ao somatório do valor médio de cada indicador ( $\Sigma \overline{1})$ dividido pelo valor máximo possível (V) para a sustentabilidade hoteleira, resultando na seguinte fórmula e que permite estabelecer o índice numa escala de valor entre 0,00 e 1,00:

$$
I S H=\frac{\sum \bar{I}}{V}
$$

onde,

ISH = Índice de Sustentabilidade Hoteleira

$\Sigma \bar{l}=$ valor médio de cada indicador

$\mathrm{V}=$ valor máximo possível da sustentabilidade hoteleira $(=140)$. 
Tabela 1 - Matriz de Indicadores de Sustentabilidade para o setor hoteleiro no concelho de Bragança

Itens/Indicadores

1 - Consciencialização dos funcionários para redução de

resíduos

2 - Separação seletiva/reciclagem

3 - Plano para os resíduos orgânicos

4 - Formação ambiental para funcionários

5 - Sensibilização ambiental dos hóspedes para redução de

recursos

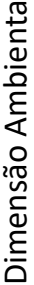

6 - Sensibilização dos hóspedes para utilização de transportes

alternativos

7 - Evita o uso de sacos plásticos

8 - Utilização de material têxtil em vez de papel

9 - Utilização de ambos os lados do papel

10 - Utilização de produtos reciclados

11 - Reutilização da água

12 - Promoção da redução do consumo de água

13 - Utilização de fontes de energia alternativa

14 - Redução do consumo de energia

15 - Construção promove a redução de energia

16 - Regulação da temperatura de forma automática

17 - Troca de roupa de quarto apenas quando solicitado

18 - Utilização de embalagens familiares

1 - Doação de excedentes alimentares

2 - Doação de material obsoleto

3 - Utilização de produtos locais na confeção da alimentação

4 - Parcerias com produtores locais

5 - Envolvimento em projetos sociais com a comunidade

6 - Promoção/venda produtos típicos locais

7 - Decoração com materiais locais

8 - Funcionários de origem local

9 - Funcionários com formação em turismo/hotelaria

10 - Adaptação a mobilidade reduzida

11 - Recomendação de património e eventos locais

1 - Longevidade do estabelecimento

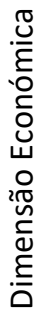

2 - Taxa de ocupação média na época alta

3 - Taxa de ocupação média na época baixa

4 - Estratégias para combater a sazonalidade

\section{Escala de avaliação}

0 - Nunca aplicado

1 - Raramente aplicado

2 - Parcialmente aplicado

3 - Frequentemente aplicado

4-Sempre aplicado
0 - Nunca aplicado

1 - Raramente aplicado

2- Parcialmente aplicado

3 - Frequentemente aplicado

4-Sempre aplicado
0 - Até 1 ano

1 - Entre 1 e 5 anos

2 - Entre 6 e 10 anos

3 - Entre 11 e 15 anos

4 - Mais de 15 anos

0 - Até $20 \%$

1 - De $21 \%$ a $40 \%$

2 - De $41 \%$ a $60 \%$

3 - De $61 \%$ a $80 \%$

4 - De $81 \%$ a $100 \%$

0 - Nunca aplicado

1 - Raramente aplicado

2 - Parcialmente aplicado

3 - Frequentemente aplicado

4 - Sempre aplicado 


$\begin{array}{ll}5 \text { - Grau de lucratividade } & 0-\text { Totalmente insatisfatório } \\ & 1-\text { Insatisfatório } \\ & 2 \text { - Baixo lucro } \\ & 3 \text { - Satisfatório/Suficiente para } \\ & \text { manter o funcionamento } \\ & 4-\text { Totalmente } \\ & \text { satisfatório/excelente } \\ \text { 6- Planeamento da atividade económica } & 0-\text { Não existe qualquer plano } \\ & \text { definido } \\ & 1-\text { Existe um plano informal } \\ & 2-\text { Realizado } 1 \text { vez nos últimos } 5 \\ & \text { anos } \\ & 3-\text { Realizado } 2 \text { vezes nos últimos } \\ & 5 \text { anos } \\ & 4-\text { Existe planeamento regular } \\ \text { (plano definido anualmente) }\end{array}$

Fonte: Adaptado de Borges et al. (2015) com contributos das autoras.

A classificação do grau de sustentabilidade do setor hoteleiro no concelho de Bragança foi dividida em cinco níveis, de acordo com a Tabela 2.

Tabela 2 - Escala do Índice de Sustentabilidade Hoteleira

\begin{tabular}{ll}
\hline Intervalo & Classificação \\
\hline $0,00<X \leq 0,20$ & Condição totalmente insatisfatória \\
$0,20<X \leq 0,40$ & Condição Insatisfatória \\
$0,40<X \leq 0,60$ & Condição moderada de sustentabilidade \\
$0,60<X \leq 0,80$ & Condição satisfatória \\
$0,80<X \leq 1,00$ & Condição ótima ou totalmente satisfatória \\
\hline
\end{tabular}

Fonte: Adaptado de Borges et al. (2015).

\section{Análise e discussão dos resultados}

\subsection{Caracterização das unidades de alojamento}

A Tabela 3 apresenta o universo das unidades de alojamento presentes no concelho de Bragança desagregado por categorias, assim como as taxas de resposta correspondentes. A taxa de resposta global foi de $49 \%$, tendo-se registado os valores mais elevados na categoria pousada, hotel e turismo em espaço rural (TER)/turismo de habitação (TH).

Das 36 unidades de alojamento que participaram neste estudo, mais de metade (56\%) são unidades TER/TH, em particular casas de campo, que corresponde à categoria de 
alojamento dominante no concelho, $22 \%$ alojamentos locais e $19 \%$ hotéis $(71 \%$ de 2 estrelas) (Tabela 3).

Tabela 3 - Unidades de alojamento do concelho de Bragança por categoria e taxa de resposta

\begin{tabular}{lccccr}
\hline \multirow{2}{*}{ Categorias } & \multicolumn{2}{c}{ Universo } & \multicolumn{2}{c}{ Respostas } & \multicolumn{2}{c}{ Taxa de } \\
& \multicolumn{2}{c}{ resposta (\%) } \\
\cline { 2 - 6 } & № & $\%$ & № & $\%$ & \\
\hline Hotel & 10 & 13,7 & 7 & 19,4 & 70,0 \\
$2^{*}$ & 6 & 8,2 & 5 & 13,9 & 83,3 \\
$3^{*}$ & 3 & 4,1 & 1 & 2,8 & 33,3 \\
$4^{*}$ & 1 & 1,4 & 1 & 2,8 & 100,0 \\
Pousada & 1 & 1,4 & 1 & 2,8 & 100,0 \\
TER/TH & 35 & 47,9 & 20 & 55,6 & 54,3 \\
Alojamento Local & 27 & 37,0 & 8 & 22,2 & 33,3 \\
\hline Total & 73 & 100 & 36 & 100 & 49,3 \\
\hline
\end{tabular}

Fonte: TP (2018) e Inquérito por questionário (2018/2019).

Neste sentido, $50 \%$ do alojamento localiza-se em meio rural, embora sejam de registar os pouco mais de $40 \%$ localizados em contexto urbano. Grande parte das unidades é recente, facto revelador do dinamismo turístico que a região tem registado nos últimos anos. Em funções há menos de um ano encontravam-se $14 \%$ das unidades inquiridas, cerca de $28 \%$ revelaram ter uma longevidade de funcionamento entre 1 e 5 anos e $25 \%$ estão no ativo há mais de 15 anos, estando por isso bem estabelecidas e consolidadas na região. Predominam as unidades de baixa capacidade de alojamento, $67 \%$ têm até 10 camas, $11 \%$ até 30 camas e apenas $8 \%$ têm disponível mais de 50 camas, sendo que cerca de $78 \%$ têm menos de 5 empregados, prevalecendo as unidades de estrutura familiar. A época de verão é a que se destaca em termos de ocupação (86\%), o que revela uma sazonalidade bastante vincada neste território, assim como o hóspede em lazer/turismo (75\%), mais de metade de origem nacional (58\%). Relativamente ao proprietário/gestor foi apurado que $80 \%$ detém formação académica superior ( $58 \%$ licenciatura e $22 \%$ mestrado) em diversas áreas, sendo que apenas $11 \%$ estão relacionadas com turismo e gestão/administração hoteleira e $6 \%$ com a engenharia do ambiente. Registam-se ainda os cerca de $6 \%$ com 20 e 30 ciclo de escolaridade. 


\subsection{Sustentabilidade económica, social e ambiental nas unidades de alojamento - aplicabilidade das práticas}

$\mathrm{Na}$ análise geral da aplicabilidade de práticas sustentáveis, cerca de $97 \%$ dos inquiridos consideraram que o seu estabelecimento tem em conta aspetos ambientais, económicos e sociais, remetendo para uma posição meramente residual (3\%) os que admitiram apenas ter em consideração o fator económico. Verifica-se que no seio de 35 indicadores, 31\% encontram-se abaixo do valor médio (2) e apenas $9 \%$ se situam acima do nível 3 , ambas as situações com particular incisão na dimensão sociocultural que adquire o valor mais elevado da média de respostas $(2,33)$, seguida da dimensão ambiental $(2,32)$ e económica $(1,93)$.

No âmbito da dimensão ambiental (Tabela 4), os indicadores selecionados posicionam-se em dois níveis: a sensibilização e a ação propriamente dita.

De acordo com Trung e Kumar (2005), a formação, a sensibilização e o envolvimento do staff e dos hóspedes constitui uma poderosa ferramenta para melhorar a eficiência da gestão dos recursos. Neste caso, destaca-se pela positiva a "consciencialização dos funcionários para a redução de resíduos", com a média de respostas mais elevada 3,39 (frequentemente aplicado), verificando-se que em $50 \%$ dos estabelecimentos é sempre praticada essa consciencialização, com particular incisão nas unidades TER (78\%), de pequena dimensão (1 a 10 camas - 72\%) e localizadas em meio rural (67\%), nas unidades mais recentes (menos de 1 ano e entre 1 e 5 anos - 50\%) e nas com mais de 15 anos (22\%). Porém, apenas $19 \%$ e $25 \%$ admitem alargar, sempre, esse esforço de consciencialização aos hóspedes relativamente à redução de recursos e ao uso de transportes alternativos, respetivamente, o que de alguma forma comprova a impopularidade da comunicação ambiental ao nível da sensibilização e colaboração dos hóspedes na economia de recursos relatada por Bohdanowicz (2006) que parece persistir, estando, por isso, ainda longe da conceção de desenvolvimento sustentável assente na importância do turista consciente e dos seus possíveis impactes ambientais.

De acordo com a literatura (Bohdanowicz, 2006; Rahman et al., 2012; Sousa \& Eusébio, 2013), a reciclagem, a redução e reutilização da água e a utilização de fontes de energia alternativa, mormente painéis solares, constituem medidas bastante populares no setor hoteleiro no sentido da promoção de uma prática ambiental sustentável. Contudo, a sua 
aplicabilidade neste estudo fica aquém do que seria expectável, sendo, com exceção da reciclagem, as medidas menos aplicadas, como demonstra a Tabela 4.

A "reutilização da água" $(1,39)$ nunca é aplicada em $36 \%$ dos estabelecimentos, embora seja de notar que $44 \%$ dos alojamentos promovam a redução do seu consumo de forma frequente e sempre. Valores que estão ainda bastante apartados dos $66 \%$ registados nos alojamentos da Região Norte, no que à utilização eficiente da água diz respeito, segundo o relatório do desempenho ambiental do alojamento em Portugal (embora se deva ressalvar que dele não constam as unidades TER), em 2019 (TP, 2020). Tanto num caso como no outro, são as unidades TER e as mais recentes que mais adotam estas medidas, e apenas um hotel de 4 estrelas admite práticas de redução de consumo de água. No âmbito da utilização eficiente da água, merece nota positiva a troca de roupa de quarto apenas quando solicitado praticada sempre (31\%) ou de forma frequente (25\%).

Ao nível da questão energética, verifica-se que a "redução do consumo de energia" é em $36 \%$ das unidades promovida de forma frequente e sempre aplicada em $28 \%$. Todavia, $50 \%$ nunca utilizam fontes de energia alternativa, mesmo assim cerca de $40 \%$ implementam esta prática, a segunda mais adotada, revelando uma percentagem bastante superior à registada (11\%) por Sousa e Eusébio (2013) no estudo que realizaram a nível nacional, demonstrando uma evolução neste domínio, e muito próxima da registada pelo Turismo de Portugal (2020). Porém, no cômputo geral, ainda estão longe dos 65\% de empresas que declaram ter adotado medidas de utilização eficiente de energia na região Norte (TP, 2020).

No âmbito da gestão eficiente dos resíduos, a reciclagem constitui uma prática assumida por mais de $90 \%$ dos alojamentos nacionais (TP, 2020). Nas unidades em estudo a "separação seletiva/reciclagem" é frequentemente (33\%) e sempre (28\%) efetuada, evidenciando um valor bastante abaixo do que se esperaria para este item, no momento e contexto atuais. Acrescenta-se que pouco mais de 30\% não têm um plano para os resíduos orgânicos. 
Tabela 4 - A dimensão ambiental no alojamento do concelho de Bragança

\begin{tabular}{|c|c|c|c|c|c|c|}
\hline Indicadores - Dimensão Ambiental & 0 & 1 & 2 & 3 & 4 & Méd. \\
\hline 1 - Consciencialização dos funcionários para redução de resíduos & 2,8 & 0,0 & 2,8 & 44,4 & 50,0 & 3,39 \\
\hline 2 - Separação seletiva/reciclagem & 8,3 & 2,8 & 27,8 & 33,3 & 27,8 & 2,69 \\
\hline 3 - Plano para os resíduos orgânicos & 33,3 & 11,1 & 25,0 & 16,7 & 13,9 & 1,67 \\
\hline 4 - Formação ambiental para funcionários & 22,2 & 5,6 & 33,3 & 16,7 & 22,2 & 2,11 \\
\hline $\begin{array}{l}5 \text { - Sensibilização ambiental dos hóspedes para redução de } \\
\text { recursos }\end{array}$ & 11,1 & 11,1 & 41,7 & 16,7 & 19,4 & 2,22 \\
\hline $\begin{array}{l}6 \text { - Sensibilização dos hóspedes para utilização de transportes } \\
\text { alternativos }\end{array}$ & 11,1 & 13,9 & 19,4 & 30,6 & 25,0 & 2,44 \\
\hline 7 - Evita o uso de sacos plásticos & 8,3 & 8,3 & 47,2 & 25,0 & 11,1 & 2,22 \\
\hline 8 - Utilização de material têxtil em vez de papel & 11,1 & 16,7 & 13,9 & 30,6 & 27,8 & 2,47 \\
\hline 9 - Utilização de ambos os lados do papel & 16,7 & 2,8 & 25,0 & 36,1 & 19,4 & 2,39 \\
\hline 10 - Utilização de produtos reciclados & 5,6 & 11,1 & 50,0 & 22,2 & 11,1 & 2,22 \\
\hline 11 - Reutilização da água & 36,1 & 19,4 & 22,2 & 13,9 & 8,3 & 1,39 \\
\hline 12 - Promoção da redução do consumo de água & 13,9 & 16,7 & 25,0 & 22,2 & 22,2 & 2,22 \\
\hline 13 - Utilização de fontes de energia alternativa & 50,0 & 5,6 & 2,8 & 2,8 & 38,9 & 1,75 \\
\hline 14 - Redução do consumo de energia & 8,3 & 2,8 & 25,0 & 36,1 & 27,8 & 2,72 \\
\hline 15 - Construção promove a redução de energia & 5,6 & 13,9 & 27,8 & 25,0 & 27,8 & 2,56 \\
\hline 16 - Regulação da temperatura de forma automática & 19,4 & 8,3 & 19,4 & 27,8 & 25,0 & 2,31 \\
\hline 17 - Troca de roupa de quarto apenas quando solicitado & 19,4 & 8,3 & 16,7 & 25,0 & 30,6 & 2,39 \\
\hline 18 - Utilização de embalagens familiares & 16,7 & 8,3 & 19,4 & 13,9 & 41,7 & 2,56 \\
\hline
\end{tabular}

Fonte: Inquérito por questionário (2018/2019).

Os hotéis são, na maioria das vezes, parte integrante da comunidade local na sua aceção mais ampla. Não só porque é comum os moradores locais constituírem grande parte da sua força de trabalho, mas também porque desempenham um papel ativo na economia local através dos produtos que adquirem e das relações que estabelecem com o cluster turístico local/regional. Assim, a aquisição de produtos a fornecedores portugueses e locais pode beneficiar a comunidade local mais próxima do hotel, estimulando as economias de menor dimensão (Sloan et al., 2013).

Tal premissa encontra-se de forma positiva espelhada neste estudo (Tabela 5). Metade dos estabelecimentos inquiridos emprega "funcionários de origem local", um facto que se destacou de forma positiva também nos estudos de Perez Jr. e Resende (2011) e Borges et al. (2015), em mais de $80 \%$ são sempre e de forma frequente utilizados "produtos locais na confeção da alimentação", o mesmo acontecendo em quase $70 \%$ com relação à "decoração com materiais locais" e a "recomendação aos hóspedes de património e eventos locais" 
ocorre sempre em $92 \%$ dos meios de alojamento. Estes resultados revelam a interação e proximidade do setor hoteleiro com a comunidade e o contexto locais, contribuindo assim para a distribuição da riqueza gerada.

Na perspetiva de Kyriakidis e Partner (2008), através do apoio a projetos e iniciativas de instituições locais, o hotel contribui para um ambiente amigável e de referência. Porém, neste caso em concreto, o "envolvimento em projetos sociais com a comunidade" ou não é aplicado de todo (22\%), é raramente (11\%) ou parcialmente aplicado (39\%), e o mesmo se verifica com a "doação de material obsoleto" $(1,81)$, sendo revelador da parca interação do setor da hotelaria com a comunidade local neste aspeto. Um resultado em linha com o que foi apurado por Perez Jr. e Resende (2011) e Borges et al. (2015), embora estes tivessem registado valores inferiores. Encontram-se, de igual modo, num nível totalmente insatisfatório as práticas "doação de excedentes alimentares" $(1,53)$, "promoção/venda de produtos típicos locais" $(1,86)$ e "adaptação a mobilidade reduzida" $(1,53)$, verificando-se que não são aplicadas de todo em 33\%, 36\% e $44 \%$ dos estabelecimentos, respetivamente. No caso da primeira, deve notar-se que o facto da maioria dos alojamentos inquiridos serem de reduzida dimensão e de não contemplarem (todas as) refeições poderá estar na origem deste baixo valor, assim como no caso da terceira prática estar relacionada com o facto da maioria das unidades em estudo serem de TER e resultantes, na maior parte dos casos, de recuperações/reconversões de casas/construções antigas, nada sensíveis a esta realidade.

Tabela 5 - A dimensão sociocultural no alojamento do concelho de Bragança

\begin{tabular}{|c|c|c|c|c|c|c|}
\hline Indicadores - Dimensão Sociocultural & 0 & 1 & 2 & 3 & 4 & Méd. \\
\hline 1- Doação de excedentes alimentares & 33,3 & 16,7 & 22,2 & 19,4 & $\overline{8,3}$ & 1,53 \\
\hline 2 - Doação de material obsoleto & 22,2 & 13,9 & 41,7 & 5,6 & 16,7 & 1,81 \\
\hline $\begin{array}{l}3 \text { - Utilização de produtos locais na confeção da } \\
\text { alimentação }\end{array}$ & 2,8 & 2,8 & 11,1 & 36,1 & 47,2 & 3,22 \\
\hline 4 - Parcerias com produtores locais & 19,4 & 5,6 & 13,9 & 27,8 & 33,3 & 2,50 \\
\hline $\begin{array}{l}5 \text { - Envolvimento em projetos sociais com a } \\
\text { comunidade }\end{array}$ & 22,2 & 11,1 & 38,9 & 22,2 & 5,6 & 1,78 \\
\hline 6 - Promoção/venda de produtos típicos locais & 36,1 & 2,8 & 19,4 & 22,2 & 19,4 & 1,86 \\
\hline 7 - Decoração com materiais locais & 2,8 & 5,6 & 22,2 & 36,1 & 33,3 & 2,92 \\
\hline 8 - Funcionários de origem local & 16,7 & 8,3 & 5,6 & 19,4 & 50,0 & 2,78 \\
\hline $\begin{array}{l}9 \text { - Funcionários com formação em } \\
\text { turismo/hotelaria }\end{array}$ & 27,8 & 16,7 & 19,4 & 16,7 & 19,4 & 1,83 \\
\hline 10 - Adaptação a mobilidade reduzida & 44,4 & 11,1 & 11,1 & 13,9 & 19,4 & 1,53 \\
\hline $\begin{array}{l}11 \text { - Recomendação de património e eventos } \\
\text { locais }\end{array}$ & 2,8 & 0,0 & 0,0 & 5,6 & 91,7 & 3,83 \\
\hline
\end{tabular}

Fonte: Inquérito por questionário (2018/2019). 
A sustentabilidade social e cultural, pese embora se verifique alguns itens com uma aplicação bastante positiva, está muito aquém em alguns aspetos que, segundo Barddal (2010, citado em Borges et al., 2015), podem por um lado levar a tensões entre os diferentes atores (empresários, residentes e turistas), e por outro contribuir para a desvalorização dos valores, produtos e até identidade locais.

No que concerne à dimensão económica (Tabela 6), todos os indicadores que a integram registaram uma média de respostas abaixo do nível 3. Da análise dos dados ficou claro que a sazonalidade é um problema bastante vincado comprometendo a viabilidade económica de muitas destas unidades, muito embora metade destas tenha definidas, sempre e de forma frequente, estratégias de combate à sazonalidade. Todavia, cerca de $38 \%$ dos alojamentos registam uma taxa de ocupação na época alta de $61 \%$ a $80 \%$ e na época baixa $54 \%$ registam menos de $20 \%$. Tal situação tende a refletir-se nos proveitos económicos obtidos. Não obstante metade dos inquiridos revelar que o lucro que obtém é satisfatório e portanto suficiente para manter o funcionamento, $13 \%$ mencionam baixos lucros e apenas um alojamento, localizado em meio urbano, referiu um lucro totalmente satisfatório. Esta situação menos favorável decorrerá, em grande parte, do facto destas unidades não disporem de um plano de atividades formal, pelo contrário, metade admite a existência de um plano informal, $17 \%$ não dispõem de qualquer plano e apenas 5 unidades referem definirem anualmente uma estratégia de planeamento.

Tabela 6 - A dimensão económica no alojamento do concelho de Bragança

\begin{tabular}{lrrrrrr}
\hline Indicadores - Dimensão Económica & \multicolumn{1}{c}{$\mathbf{0}$} & $\mathbf{1}$ & $\mathbf{2}$ & $\mathbf{3}$ & \multicolumn{1}{c}{$\mathbf{4}$} & Méd. \\
\hline 1 - Longevidade do estabelecimento & 13,9 & 27,8 & 19,4 & 13,9 & 25,0 & 2,08 \\
2 - Taxa de ocupação média na época alta & 12,5 & 16,7 & 20,8 & 37,5 & 12,5 & 2,21 \\
3 - Taxa de ocupação média na época baixa & 54,2 & 20,8 & 16,7 & 4,2 & 4,2 & 0,83 \\
4 - Estratégias para a sazonalidade & 19,4 & 2,8 & 27,8 & 25,0 & 25,0 & 2,33 \\
5 - Grau de lucro & 0,0 & 12,5 & 33,3 & 50,0 & 4,2 & 2,46 \\
6 - Planeamento da atividade económica & 16,7 & 50,0 & 4,2 & 8,3 & 20,8 & 1,67 \\
\hline
\end{tabular}

Fonte: Inquérito por questionário (2018/2019).

Tendo em conta os dados analisados registou-se um índice de sustentabilidade hoteleira de 0,56 (ISH =78,9/140), medido numa escala de 0 a 1 , o que é revelador de uma condição moderada de sustentabilidade. Trata-se de um valor superior ao registado por Borges et al. 
(2015), 0,39, na rede hoteleira de Barra Grande (Maraú-Bahia). Embora se esteja já perante um contexto de sustentabilidade positivo, alicerçado e alavancado sobretudo por algumas medidas de cariz ambiental e social/cultural, a adoção de práticas sustentáveis é ainda incipiente em vários aspetos nas três dimensões abordadas, sugerindo uma repercussão reduzida no desenvolvimento sustentável deste território. A razão potencial para que tal aconteça prende-se desde logo com o facto das práticas sustentáveis serem dispendiosas, sobretudo as ambientais. Verifica-se que as práticas mais frequentes nas unidades de alojamento de Bragança estão, tal como apurado nos estudos de Bohdanowicz (2006) ou Sousa e Eusébio (2013), relacionadas sobretudo com gestão de recursos e que requerem um baixo investimento, não obstante lhes ser reconhecido grande impacte no ambiente, em detrimento, por exemplo, da reutilização da água e da utilização de fontes de energia alternativa (incluindo painéis solares) que pressupõem investimentos mais avultados em equipamento. Note-se que, mais de 3/4 desta amostra é composta por unidades com menos de 50 camas e menos de 5 empregados, para além de que cerca de $50 \%$ das unidades têm uma taxa de ocupação-cama até $20 \%$ na época baixa e cerca de $40 \%$ não atingem metade da ocupação em época alta. De acordo com Fotiadisa et al. (2013), os altos custos de investimento e a incerteza do seu retorno são algumas das barreiras que condicionam a adoção de práticas sustentáveis pelos alojamentos de pequena e média dimensão.

Não obstante, outras práticas foram identificadas com reduzida implementação, apesar de não serem muito exigentes em termos financeiros, como o aproveitamento de resíduos orgânicos, a não utilização de sacos plásticos ou a utilização de produtos reciclados, o que decerto será revelador da falta de conhecimento ou preparação para tal. Neste âmbito, acrescenta-se que a consciência sobre turismo responsável dos proprietários constitui outro fator influenciador da adoção de medidas sustentáveis nas pequenas unidades (Radwan, Jones, \& Minoli, 2012, citados em Musavengane, 2019), mas o baixo nível de formação na área turística/hoteleira dos proprietários/gestores e dos próprios empregados assim como a baixa aposta na formação ambiental dos funcionários pode, de alguma forma, estar a condicionar a sua implementação, sendo por isso crucial uma aposta na formação sobre turismo responsável. 
Embora medianos, os resultados apurados neste estudo são mais positivos do que os obtidos por outros, realizados com esta metodologia ou similar, que revelaram uma condição insatisfatória (Perez Jr. \& Resende, 2011; Borges et al., 2015). Porém, os resultados verificados na dimensão ambiental são um tanto ou quanto inferiores, em alguns parâmetros, aos de Sousa e Eusébio (2013).

Na sequência da análise geral, a avaliação ao nível de cada unidade de alojamento permite perceber o nível de comprometimento de cada estabelecimento com o desenvolvimento sustentável através da adoção de práticas sustentáveis. Em apenas $14 \%$ (total de 5 unidades) a média de respostas aos indicadores foi superior ao nível 3 (nunca alcançando o nível 4), detendo estas, por isso, os valores mais elevados do ISH, posicionados entre a condição satisfatória e ótima. Todas elas são unidades TER, de baixa dimensão, contrariando as evidências relatadas, por exemplo, no estudo de Viegas (2008, citada em Sousa \& Eusébio, 2013) ou de Barros e Dieke (2008, citados em Kularatne et al., 2019) que concluíram que grandes hotéis são mais eficientes que os pequenos hotéis, e aproximandose mais dos resultados apurados por Kularatne et al. (2019), embora seja justo referir as controvérsias em torno desta relação. Mesmo analisando apenas os hotéis por categoria não surge de forma clara, no presente estudo, a tendência identificada por Sousa e Eusébio (2013) de que os hotéis de categoria superior adotam mais medidas de proteção ambiental. As unidades com melhor desempenho estão em funcionamento há relativamente poucos anos (1 a 5 anos e 5 a 10 anos) o que demonstra uma maior consciencialização e preocupação para com as questões da sustentabilidade neste sector mas, que também será justificado pelas exigências impostas pela legislação em vigor. Os valores mais baixos de ISH registam-se nos alojamentos locais.

Quanto ao índice de sustentabilidade individual, verifica-se que cerca de $33 \%$ estão posicionadas nos níveis satisfatório e ótimo (Tabela 7), ao contrário do que fora apurado por Borges et al. (2015) no seu estudo, com apenas 5\%, sendo que a maioria, $65 \%$, revelou uma condição insatisfatória que, neste estudo, em conjunto com o nível totalmente insatisfatório se cifra nos $11 \%$, verificados quase em exclusivo nas unidades de alojamento local. 
Tabela 7 - Índice de Sustentabilidade Hoteleira por unidade de alojamento

\begin{tabular}{lll}
\hline ISH intervalo & $\%$ & Classificação \\
\hline $0,00-0,20$ & 2,8 & Condição totalmente insatisfatória \\
$0,20-0,40$ & 8,3 & Condição Insatisfatória \\
$0,40-0,60$ & 55,6 & Condição moderada de sustentabilidade \\
$0,60-0,80$ & 25,0 & Condição satisfatória \\
$0,80-1,00$ & 8,3 & Condição ótima ou totalmente satisfatória \\
\hline
\end{tabular}

Fonte: Inquérito por questionário (2018/2019).

Este resultado constitui um sinal positivo de uma mudança em curso, não obstante a maior parte das unidades avaliadas, onde se incluem todos os hotéis, ter obtido um valor entre os 0,40 e 0,60 (condição mediana) e ser notória a fragilidade deste contexto de sustentabilidade.

\section{Conclusões}

A sustentabilidade tem-se posicionado como um dos pilares essenciais da atividade turística contemporânea pautada, cada vez mais, por critérios de exigência, sendo por isso presença e preocupação assídua nos discursos, políticas e recomendações direcionados para o setor. Os diversos sistemas de indicadores assentes nas abordagens ambiental, social, cultural, políticas institucionais e turísticas têm contribuído para a verificação e avaliação do nível de sustentabilidade do turismo, assumindo desta forma um papel preponderante no auxílio dos gestores na delineação de estratégias com vista ao robustecimento do turismo sustentável.

O setor da hotelaria há muito que se tem perfilado na adoção de práticas sustentáveis, já que há um entendimento geral de que esta conduta é crucial para garantir perspetivas de negócios a longo prazo e uma maior rentabilidade (compreensão de que a sustentabilidade traz valor a numerosos aspetos da performance hoteleira). Mas, apesar dos avanços que se têm verificado neste setor, muito mais há para fazer para que a sustentabilidade passe a ser considerada central e passe a constar da filosofia dos negócios, não apenas para aumentar a vantagem competitiva, mas também para reduzir o impacte ambiental geral da sociedade.

O propósito deste estudo era a aferição do nível de implementação de práticas sustentáveis nas unidades de alojamento turístico do concelho de Bragança, tendo-se apurado um ISH 
$(0,56)$ que revela uma condição moderada de sustentabilidade. Assim, não obstante os resultados positivos referentes a algumas práticas chama-se a atenção para a fragilidade deste contexto de sustentabilidade, devido ao nível insatisfatório que determinadas práticas apresentam, havendo ainda muito a ser feito para que o setor do alojamento de Bragança contribua de forma efetiva para o turismo sustentável. Embora as unidades de alojamento do concelho de Bragança já apresentem ações que visam a sustentabilidade, como a diminuição do uso da água ou energia, alguns itens mais complexos e que envolvem custos mais elevados ainda não foram implementados. Facto que poderá legitimar questionamento sobre a real intencionalidade da adoção destas práticas, a efetiva proteção do ambiente ou a mera redução de custos, mas que invariavelmente poderá estar relacionado com a pequena dimensão da maior parte das unidades de alojamento analisadas.

Os resultados obtidos neste estudo decerto trazem um contributo interessante à literatura existente sobre o tema assim como poderão induzir novas linhas de investigação. A metodologia deve ser aplicada numa base territorial mais alargada, incluindo um número mais elevado de unidades, com indicadores mais especificados, uma vez que os utilizados conferem uma leitura mais global. O carácter exploratório, a taxa de resposta mediana e registada sobretudo nas unidades de alojamento TER, facto que poderá estar a influenciar os resultados obtidos, constituem as principais limitações.

Numa perspetiva mais prática, os resultados apurados podem e devem constituir uma ferramenta de apoio aos meios de alojamento deste concelho, sobretudo na tomada de consciência sobre o nível atual de aplicabilidade das práticas gerais destas unidades e dos progressos realizados, podendo influenciar futuros comportamentos, atitudes e ações com o objetivo de melhorar a sua performance em relação a outros.

\section{Referências Bibliográficas}

Asadi, S. et al. (2020). Investigating influence of green innovation on sustainability performance: A case on Malaysian hotel industry. Journal of Cleaner Production, 258, 1-15.

Aznar, J. P., Sayeras, J. M., Galiana, J., \& Rocaforte, A. (2016). Sustainability Commitment, New Competitors' Presence, and Hotel Performance: The Hotel Industry in Barcelona. Sustainability, 8, 755, 1-13.

Bader, E. E. (2005). Sustainable hotel business practices. Journal of Retail \& Leisure Property, 5(1), 70-77. 
Bohdanowicz, P. (2005). European hoteliers' environmental attitudes: Greening the business. Cornell Hotel \& Restaurant Administration Quarterly, 46(2), 188-204.

Bohdanowicz, P. (2006). Environmental awareness and initiatives in the Swedish and Polish hotel industries survey results. International Journal of Hospitality Management, 25(4), 662-682.

Bohdanowicz, P., \& Martinac, I. (2003). Attitudes towards sustainability in chain hotels - Results of a European survey. In: Paper Presented at the CIB International Conference on Smart and Sustainable Built Environment, $10 \mathrm{pp}$.

Bohdanowicz, P., \& Zientara, P. (2008). Corporate social responsibility in hospitality: Issues and implications. A case study of Scandic. Scandinavian Journal of Hospitality and Tourism, 8(4), 271-293.

Borges, C., Ferraz, M., \& Borges, A. (2015). Turismo sustentável e meios de hospedagem: uma avaliação da sustentabilidade hoteleira em Barra Grande, Maraú (BA). Revista Turismo - Visão e Ação - Eletrónica, 17(3), 601-629.

Careto, H., \& Lima, S. (2006). Turismo e Desenvolvimento Sustentável 1. Lisboa: Geota - Grupo de Estudos de Ordenamento do Território e Ambiente.

Choi, H.-M., Kim, W. G., Kim, Y. J., \& Agmapisarn, C. (2019). Hotel environmental management initiative (HEMI) scale development. International Journal of Hospitality Management, 77, 562-572.

Erdogan, N., \& Baris, M. E. (2007). Environmental Protection Programs and Conservation Practices of Hotels in Ankara, Turkey. Tourism Management, 28(2), 604-614.

Font, X. (2002). Environmental certification in tourism and hospitality: progress, process and prospects. Tourism Management, 23(3), 197-205.

Fotiadisa, A. K., Vassiliadis, C. A., \& Rekleitis, P. D. (2013). Constraints and benefits of sustainable development: a case study based on the perceptions of small-hotel entrepreneurs in Greece. Anatolia, 24(2), 144-161.

Gössling, S., \& Buckley, R. (2016). Carbon labels in tourism: persuasive communication? Journal of Cleaner Production, 111, 358-369.

Gossling, S., \& Peeters, P.M. (2015). Assessing tourism's global environmental impact 1900-2050. Journal of Sustainable Tourism, 23(5), 639-659.

Gupta, A., Dash, S., \& Mishra, A. (2019). Self/other oriented green experiential values: Measurement and impact on hotel-consumer relationship. International Journal of Hospitality Management, 83, 159-168.

Hernández-Perlines, F. (2016). Entrepreneurial orientation in hotel industry: Multi-group analysis of quality certification. Journal of Business Research, 69, 4714-4724.

INE - Instituto Nacional de Estatística (2019). Anuário Estatístico da Região Norte 2018. Disponível em: https://www.ine.pt/xportal/xmain?xpid=INE\&xpgid=ine_publicacoes. Acedido em 26 set 2019.

Kasim, A., Gursoy, D., Okumus, F., \& Wong, A. (2014). The importance of water management in hotels: a framework for sustainability through innovation. Journal of Sustainable Tourism, 22(7), 1090-1107.

Kim, Y., \& Statman, M. (2012). Do Corporations Invest Enough in Environmental Responsibility? Journal of Business Ethics, 105(1), 115-129.

Kularatne, T., Wilson, C., Månsson, J., Hoang, V., \& Lee, B. (2019). Do environmentally sustainable practices make hotels more efficient? A study of major hotels in Sri Lanka. Tourism Management, 71, 213-225.

Kyriakidis, A., \& Partner, G. M. (2008). Too Hot to Handle? The Hospitality Industry Faces. In Blanke, J. \& Chiesa, T. The travel \& Tourism Competitiveness Report: Balancing Economic Development and Environmental Sustainability (472, 71-81). Geneva: World Economic Forum.

Lenzen, M., Sun, Y.-Y., Faturay, F., Ting, Y.-P., Geschke, A. \& Malik, A. (2018). The carbon footprint of global tourism. Nature Climate Change, 8(6), 522.

Li, D., Zheng, M., Cao, C., Chen, X., Ren, S. \& Huang, M. (2017). The impact of legitimacy pressure and corporate profitability on green innovation: evidence from China top 100. Journal of Cleaner Production, 141, 41-49. 
Mak, A. H. N., \& Chang, R. G. Y. (2019). The driving and restraining forces for environmental strategy adoption in the hotel Industry: A force field analysis approach. Tourism Management, 73, 48-60.

Melissen, F., Koens, K., Brinkman, M., \& Smit, B. (2016). Sustainable development in the accommodation sector: a social dilemma perspective. Tourism Management Perspectives, 20, 141-150.

Mensah, I., \& Mensah, R. D. (2013). Internacional tourist's enviromental attitude towards hotels in Accra. Tourismos: An Internacional Multidisciplinary Journal of Tourism, 8(2), 57-75.

Mihalič, T. (2000). Environmental management of a tourist destination. A factor of tourism competitiveness. Tourism Management, 21, 65-78.

Molina-Azorín, J. F., Claver-Cortes, E., Pereira-Moliner, J., \& Tarí, J. J. (2009). Environmental practices and firm performance: an empirical analysis in the Spanish hotel industry. Journal of Cleaner Production, 17(5), 516-524.

Musavengane, R. (2019). Small hotels and responsible tourism practice: Hoteliers' perspectives. Journal of Cleaner Production, 220, 786-799.

Nilashi, M., Ahani, A., Esfahani, M. D., Yadegaridehkordi, E., Samad, S., Ibrahim, O., Sharef, N. M. \& Akbari, E. (2019). Preference learning for eco-friendly hotels recommendation: a multi-criteria collaborative filtering approach. Journal of Cleaner Production, 215, 767-783.

Perez Jr., M. R., \& Resende, D. C. (2011). Gestão da sustentabilidade no segmento hoteleiro: estudo dos meios de hospedagem de Monte Verde, MG. Caderno Virtual de Turismo, 11(2), 234-252.

Preziozi, M., Tourais, P., Acampora, A., Videira, N., \& Merli, R. (2019). The role of environmental practices and communication on guest loyalty: Examining EU-Ecolabel in Portuguese hotels. Journal of Cleaner Production, 237, 1-13.

Rahman, I., Reynolds, D., \& Svaren, S. (2012). How “green” are North American hotels? An exploration of lowcost adoption practices. International Journal of Hospitality Management. 31(3), 720-727.

Rodríguez-Anton, J. M., Alonso-Almeida, M. M., Celemín, M. S., \& Rubio, L. (2012). Use of different sustainability management systems in the hospitality industry. The case of Spanish hotels. Journal of Cleaner Production, 22(1), 76-84.

Santos, R. A., Mexas, M. P., \& Meiriño, M. J. (2017). Sustainability and hotel business: criteria for holistic, integrated and participative development. Journal of Cleaner Production, 142(1), 217-224.

Santos, R. A., Mexas, M. P., Meiriño, M. J., Sampaio, M. C., \& Costa, H. G. (2020). Criteria for assessing a sustainable hotel business. Journal of Cleaner Production, 262, 1-10.

Santos, S., Barbosa, P., \& Bártolo, T. (2009). Turismo sustentável e a sua importância para o sector em Portugal. Disponível em: http://www.sustentare.pt/pdf/Research5-\%20Turismo-Sustentavel.pdf. Acedido em 15 mai 2019.

Sloan, P., Legrand, W., \& Chen, J. S. (2013). Sustainability in the hospitality industry: principles of sustainable operations. London: Routledge.

Sousa, N., \& Eusébio, C. (2013). Análise da gestão ambiental nos hotéis portugueses. Revista Portuguesa e Brasileira de Gestão, 12(2), 59-74.

TP - Turismo de Portugal (2018). Registo Nacional de Empreendimentos Turísticos. Disponível em: https://registos.turismodeportugal.pt/. Acedido em 17 dez 2018.

TP - Turismo de Portugal (2020). Desempenho Ambiental do Alojamento em Portugal | 2019. Boas Práticas nos Estabelecimentos Hoteleiros, Aldeamentos e Apartamentos Turísticos. Disponível em: https://travelbi.turismodeportugal.pt/pt-pt/Paginas/desempenho-ambiental-do-alojamento-em-portugal2013-2017.aspx. Acedido em 23 jun 2020.

Trung, D. N., \& Kumar, S. (2005). Resource use and waste management in Vietnam hotel industry. Journal of Cleaner Production, 13, 109-116.

UN - United Nations (1987). Our Common Future - Report of the World Commission on Environment and Development. Nairobi: United Nations. 
UN - United Nations (2015). Transforming our world: the 2030 Agenda for sustainable development. Disponível em: https://sustainabledevelopment.un.org/post2015/transformingourworld/publication. Acedido em 15 mai 2019.

WTO - World Tourism Organization (2011). Tourism and Sustainability. Disponível em: https://www.unwto.org/. Acedido em 15 mai 2019.

Yılmaz, H., \& Yılmaz, S. (2016). Corporate Social Responsibility in Hotel Businesses. Otel Işletmelerinde Kurumsal Sosyal Sorumluluk, 16(2), 89-100. 